\title{
TLRs and IFNs: critical pieces of the autoimmunity puzzle
}

\author{
Argyrios N. Theofilopoulos
}

Department of Immunology and Microbial Science, Scripps Research Institute, La Jolla, California, USA.

\begin{abstract}
Discoveries revealing the molecular basis of innate immune responses, particularly the identification of Toll-like receptors (TLRs) as the major recognition sensors for microbial and even self-molecules, have provided new insights into the pathogenesis of both systemic and organ-specific autoimmune diseases. These insights will permit the development of novel treatment modalities for these disorders.
\end{abstract}

For three decades, my laboratory has investigated the cause of autoimmune diseases, specifically of systemic autoimmunity as exemplified in lupus, the prototypic autoimmune disease. Why are pathogenic antibodies synthesized in lupus? Why are these antibodies so often directed against the same antigens, mostly components of nuclei, but sometimes other proteins as well? Foremost, what are the genetic defects that permit lupus to develop? These questions, first raised more than 50 years ago, have begun to give way to modern methods of molecular genetics. We now foresee an era in which the treatment of autoimmune diseases will truly target the inciting cause.

Early on, our research inclined toward analysis of the visible endpoints of disease, such as injury of the kidneys and other parenchymal organs. Our efforts focused on immune complexes as the major mediators of inflammation, and our publications in the $J C I(1,2)$ and elsewhere (3) described assay systems for the detection and characterization of these mediators and their roles in a broad spectrum of diseases (4). With the description of several spontaneous mouse models with lupuslike manifestations (5) and the advent of molecular techniques, we then attempted to define the structural characteristics of autoantibodies and autoreactive $\mathrm{T}$ cells, identify tolerance defects, and characterize the multiple loci (and genes) associated with this polygenic disorder. Similar studies were concurrently performed by other investigators, the vast majority addressing abnormalities within the adaptive immune

Conflict of interest: The author has declared that no conflict of interest exists.

Citation for this article: $J$ Clin Invest.

2012;122(10):3464-3466. doi:10.1172/JCI63835. system, which was thought to be centrally responsible for the pathogenesis of lupus. In 1998, we published two papers in the $J C I$ demonstrating that signaling by IFN- $\gamma$ was an important contributor to disease pathogenesis. We found that lupus-prone MRL-Fas ${ }^{\text {pr }}$ mice lacking the IFN- $\gamma$-encoding gene (6), or treated with intramuscular injections of a vector encoding an IFN- $\gamma \mathrm{R} /$ IgG1Fc fusion protein to block IFN- $\gamma$ function (7), showed significant reduction in all disease parameters and had extended survival. Notably, these effects were observed even when this treatment was initiated at relatively late stages of disease. Others described similar disease-reducing effects in this and additional lupus-predisposed strains lacking Ifng or Ifngr I (8-10) or treated with recombinant soluble IFN- $\gamma \mathrm{R}$ (11) or anti-IFN- $\gamma$ antibody $(11,12)$.

Overall, these and other findings, such as the reduced disease incidence and severity in predisposed mice that lacked MHC class II or TCR $\beta$ expression, clearly established the role of the adaptive immune system in lupus pathogenesis. But the central questions remained unanswered: What was the origin of the pathogenic process, and what was the primary trigger for this disease? A congruence of findings recently implicated the innate immune system as the culprit. Retrospectively, an initial hint for a role of innate sensors, specifically nucleic acid-sensing TLRs and production of type I IFNs, was the early finding that sera of lupus patients had high levels of type I IFNs $(13,14)$. Moreover, IFN- $\alpha$ in lupus sera promoted maturation of monocytes to efficient antigen-presenting cells (15), and there was a predominance of type I IFNinducible genes in microarray profiles of PBMCs from lupus patients $(16,17)$. More direct evidence of the role of type I IFNs was obtained in our study in which NZB mice homozygous, and even heterozygous, for Ifnar1 deletion showed significant disease reduction (18). Within this context, early studies of Ronnblom and colleagues were of high relevance. These authors showed that sera of lupus patients or complexes of autoantibodies with plasmid DNA or apoptotic materials induced strong production of type I IFNs by plasmacytoid DCs (19). A major advance in this area was the subsequent finding of Marshak-Rothstein and colleagues that chromatin-antichromatin immune complexes mediated proliferation of B cells expressing a BCR with rheumatoid factor activity, and that this effect was dependent on the uptake of such complexes and engagement of endosomal TLR9 (20). This finding, together with extraordinary developments in the characterization of TLRs and other sensors for pathogen-derived molecules, particularly nucleic acids, opened up a new chapter in our understanding of autoimmune disease initiation (20-22).

Importantly, it became clear that not only foreign nucleic acids, but also selfnucleic acids, can provoke an endosomal TLR-mediated inflammatory response, and both DNA- and RNA-containing materials may elicit such responses $(20,22)$. Accordingly, Tlr7 deletion in MRL-Fas ${ }^{l p r}$ mice, and particularly in severe lupus-developing male BXSB mice with a $T l r 7$ gene duplication, led to disease reduction. Paradoxically, however, $\operatorname{Tl} r 9$ deletion in MRL-Fas ${ }^{l p r}$ mice resulted in enhanced disease despite decreases in anti-DNA autoantibodies, suggestive of a protective role of this TLR. The apparent protective effect of TLR9 was questioned by our observation that B6-Fas ${ }^{p r}$ and BXSB mice congenic for the $3 d$ mutation of the UNC93B1 protein - in which signaling by all nucleic acid-sensing endosomal TLRs (TLR3, TLR7, and TLR9) is extinguished - showed significant reductions in all disease parameters and the diverse autoantibodies associated with this disease (23). Similarly, other studies showed that mice carrying double deletion 


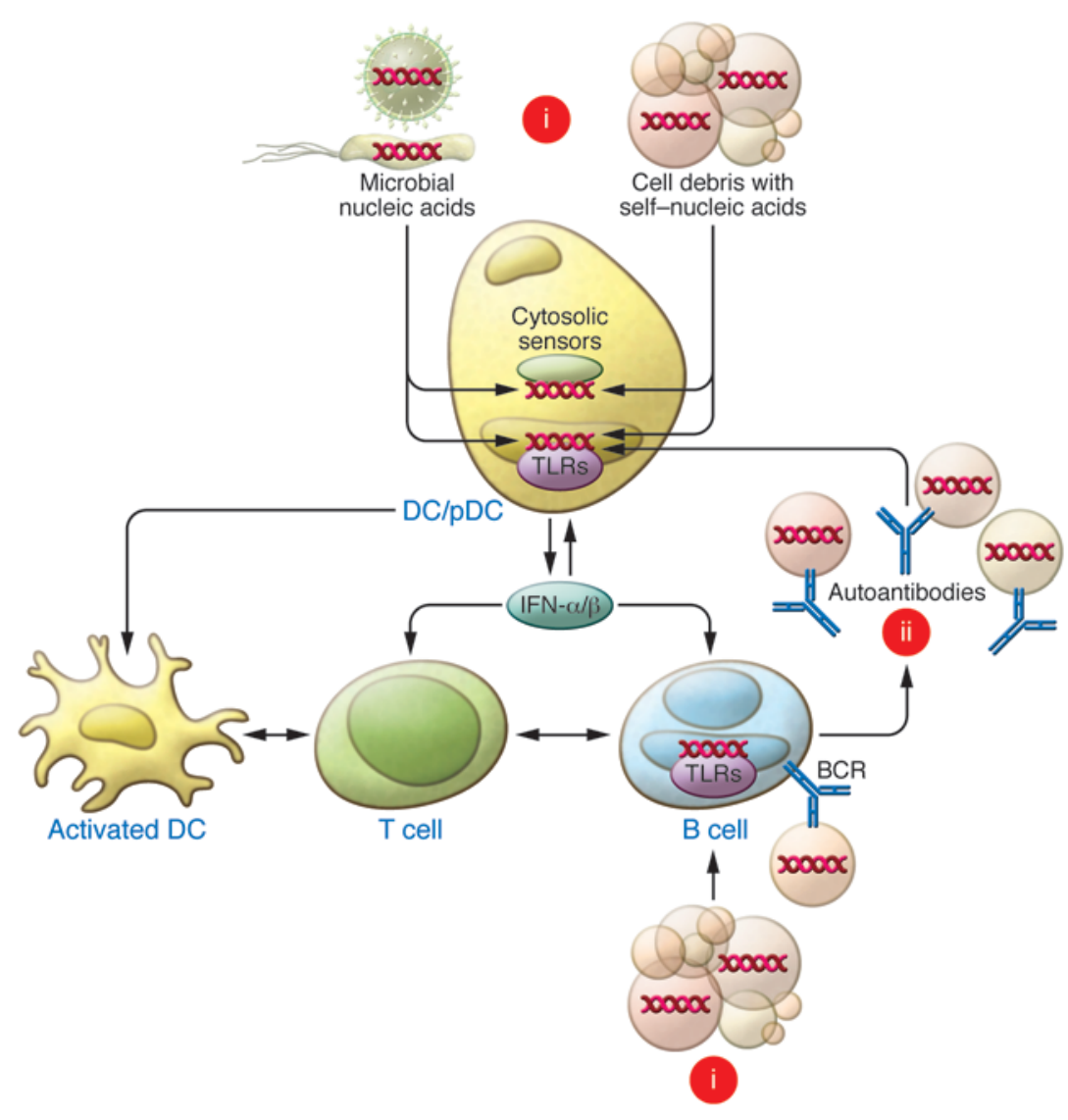

of $\operatorname{Tr} 7$ and $\operatorname{Tl} 9$ had stronger disease reduction than those carrying the single $T / r 7$ deletion. These results suggested that both TLR7 and TLR9 exert disease-promoting effects and that TLR7 engagement is more pathogenic than TLR9 engagement (24). The differential effects of these TLRs may be attributed to increased availability of TLR7-engaging, RNA-containing particles and/or increased downstream signaling by TLR7 compared with TLR9. In this regard, it should also be noted that TLR9 has higher affinity than TLR7 for UNC93B1, which traffics nucleic acid-sensing TLRs from the ER to endolysosomes in which ligand binding occurs. Therefore, deficiency of TLR9 would allow higher availability of UNC93B1 for trafficking of the more pathogenic TLR7. This provides a potential explanation for the disease-promoting effect of Tlr9 deletion.

In lupus, self-nucleic acids may evade the various mechanisms that normally prevent engagement of endosomal TLRs due to defective function of nucleases, protection from nucleases after complexing with autoantibodies and uptake by plasmacytoid/ conventional DCs through $\mathrm{Fc} \gamma \mathrm{R}$, and high frequency of autoreactive B cells with speci- ficity for nucleic acids, nucleoproteins, and related immune complexes $(20,22)$. Some nucleic acid-containing particles may be contributed by enhanced apoptosis or defective removal of apoptotic materials. Indeed, numerous defects in molecules involved in clearance of apoptotic debris are associated with antinuclear autoantibodies and clinical features of SLE in humans and mice $(22,25)$. Taking all these findings into consideration, we posited that systemic autoimmunity in predisposed individuals may proceed through a two-step process (Figure 1): an initiation step, in which uptake of apoptotic materials and nucleic acids induces an innate response and production of proinflammatory cytokines, especially type I IFNs, leading to activation of antigen-presenting DCs and B cells, followed by an amplification step, in which engagement of previously quiescent lowaffinity autoreactive helper T cells leads to production of autoantibodies, formation of immune complexes, and uptake by plasmacytoid DCs (pDCs), DCs, and B cells, thereby perpetuating the inflammatory process.

The long journey to defining the pathogenesis of autoimmune syndromes has not yet been completed, but the end is clearly

\section{Figure 1}

The two-phase paradigm for lupus pathogenesis. In the initiation phase (i), self-nucleic acids and associated proteins in apoptotic cell debris are taken up by DCs and nontolerant $B$ cells with specific BCRs, leading to endosomal TLR engagement, production of type I IFNs, antigen presentation to helper $\mathrm{T}$ cells, and production of autoantibodies. In the amplification phase (ii), autoantibodies complexed with particles containing nucleic acids and proteins are taken up by pDCs, DCs, and B cells, thereby creating an autoamplification loop that sustains the pathogenic response. In some instances, recognition of nucleic acids may be mediated by cytosolic sensors, and microbial nucleic acids may also precipitate these events. in reach. The findings discussed in relation to lupus are likely applicable to the pathogenesis of almost every other systemic and organ-specific autoimmune disease, in which evidence of the involvement of TLRs and IFNs has begun to emerge $(26,27)$. The evidence cited above strongly implies that endosomal TLRs and recognition of self-nucleic acids under sterile conditions are intimately involved in eliciting autoimmune responses. However, in some instances, microbial nucleic acids - alone or in combination with self-nucleic acids released from infected or damaged tissues - may also contribute, as might be the case with non-TLR cytosolic nucleic acid sensors $(22,28)$. Overall, definition of the diverse innate immune sensors and their trafficking and signaling pathways are likely to provide novel molecular targets for interventions in autoimmune/inflammatory disorders, and these treatments are likely to be far more specific and efficacious than the relatively crude cytoreductive methods that are presently applied.

\section{Acknowledgments}

I thank Bruce Beutler and Roberto Baccala for critical review of this article and 
suggestions, as well as all current and former members of my laboratory. Because of space limitations, most references are reviews in which the original citations can be found. The work of the author is supported by the National Institute of Arthritis and Musculoskeletal and Skin Diseases.

Address correspondence to: Argyrios N. Theofilopoulos, Scripps Research Institute, Department of Immunology and Microbial Science, 10550 North Torrey Pines Road, La Jolla, California 92037, USA. Phone: 858.784.8135; Fax: 858.784.8361; E-mail: argyrio@scripps.edu.

1. Theofilopoulos AN, Wilson CB, Dixon FJ. The Raji cell radioimmune assay for detecting immune complexes in human sera. JClin Invest. 1976;57(1):169-182.

2. Theofilopoulos AN, Eisenberg RA, Dixon FJ. Isolation of circulating immune complexes using Raji cells. Separation of antigens from immune complexes and production of antiserum. J Clin Invest. 1978; 61(6):1570-1581.

3. Theofilopoulos AN, Wilson CB, Bokisch VA, Dixon FJ. Binding of soluble immune complexes to human lymphoblastoid cells. II. Use of Raji cells to detect circulating immune complexes in animal and human sera. J Exp Med. 1974;140(5):1230-1244.

4. Theofilopoulos AN, Dixon FJ. The biology and detection of immune complexes. Adv Immunol. 1979; 28:89-220.

5. Theofilopoulos AN, Dixon FJ. Murine models of systemic lupus erythematosus. Adv Immunol. 1985; 37:269-390.

6. Balomenos D, Rumold R, Theofilopoulos AN.
Interferon-gamma is required for lupus-like disease and lymphoaccumulation in MRL-lpr mice. J Clin Invest. 1998;101(2):364-371.

7. Lawson BR, et al. Treatment of murine lupus with cDNA encoding IFN-gammaR/Fc. J Clin Invest. 2000;106(2):207-215.

8. Peng SL, Moslehi J, Craft J. Roles of interferongamma and interleukin-4 in murine lupus. J Clin Invest. 1997;99(8):1936-1946.

9. Haas C, Ryffel B, Le Hir M. IFN-gamma receptor deletion prevents autoantibody production and glomerulonephritis in lupus-prone (NZB x NZW) F1 mice. J Immunol. 1998;160(8):3713-3718.

10. Schwarting A, Wada T, Kinoshita K, Tesch G, Kelley VR. IFN-gamma receptor signaling is essential for the initiation, acceleration, and destruction of autoimmune kidney disease in MRL-Fas(lpr) mice. J Immunol. 1998;161(1):494-503.

11. Ozmen L, Roman D, Fountoulakis M, Schmid G, Ryffel B, Garotta G. Experimental therapy of systemic lupus erythematosus: the treatment of $\mathrm{NZB} / \mathrm{W}$ mice with mouse soluble interferon-gamma receptor inhibits the onset of glomerulonephritis. Eur J Immunol. 1995;25(1):6-12.

12. Jacob CO, van der Meide PH, McDevitt HO. In vivo treatment of (NZB X NZW)F1 lupus-like nephritis with monoclonal antibody to gamma interferon. J Exp Med. 1987;166(3):798-803.

13. Hooks JJ, Moutsopoulos HM, Geis SA, Stahl NI, Decker JL, Notkins AL. Immune interferon in the circulation of patients with autoimmune disease. NEngl J Med. 1979;301(1):5-8.

14. Preble OT, Black RJ, Friedman RM, Klippel JH, Vilcek J. Systemic lupus erythematosus: presence in human serum of an unusual acid-labile leukocyte interferon. Science. 1982;216(4544):429-431.

15. Blanco P, Palucka AK, Gill M, Pascual V, Banchereau J. Induction of dendritic cell differentiation by IFNalpha in systemic lupus erythematosus. Science. 2001;294(5546):1540-1543

16. Baechler EC, et al. Interferon-inducible gene expression signature in peripheral blood cells of patients with severe lupus. Proc Natl Acad Sci U S A. 2003;100(5):2610-2615.

17. Bennett $\mathrm{L}$, et al. Interferon and granulopoiesis signatures in systemic lupus erythematosus blood. J Exp Med. 2003;197(6):711-723.

18. Santiago-Raber ML, et al. Type-I interferon receptor deficiency reduces lupus-like disease in NZB mice. J Exp Med. 2003;197(6):777-788.

19. Ronnblom L, Eloranta ML, Alm GV. The type I interferon system in systemic lupus erythematosus. Arthritis Rheum. 2006;54(2):408-420.

20. Marshak-Rothstein A, Rifkin IR. Immunologically active autoantigens: the role of toll-like receptors in the development of chronic inflammatory disease. Annu Rev Immunol. 2007;25:419-441.

21. Moresco EM, Lavine D, Beutler B. Toll-like receptors. Curr Biol. 2011;21(13):R488-493.

22. Theofilopoulos AN, Kono DH, Beutler B, Baccala R. Intracellular nucleic acid sensors and autoimmunity. J Interferon Cytokine Res. 2011;31(12):867-886.

23. Kono DH, et al. Endosomal TLR signaling is required for anti-nucleic acid and rheumatoid factor autoantibodies in lupus. Proc Natl Acad SciUS A. 2009;106(29):12061-12066.

24. Theofilopoulos AN, et al. Sensors of the innate immune system: their link to rheumatic diseases. Nat Rev Rheumatol. 2010;6(3):146-156.

25. Baccala R, Hoebe K, Kono DH, Beutler B, Theofilopoulos AN. TLR-dependent and TLR-independent pathways of type I interferon induction in systemic autoimmunity. Nat Med. 2007;13(5):543-551.

26. Theofilopoulos AN, Baccala R, Beutler B, Kono DH. Type I interferons (alpha/beta) in immunity and autoimmunity. Annu Rev Immunol. 2005;23:307-335.

27. Baccala R, Kono DH, Theofilopoulos AN. Interferons as pathogenic effectors in autoimmunity. Immunol Rev. 2005;204:9-26.

28. Barbalat R, Ewald SE, Mouchess ML, Barton GM. Nucleic acid recognition by the innate immune system. Annu Rev Immunol. 2011;29:185-214. 